\title{
ERICSSON, Ingolf, SANKE, Markus, Aktuelle Forschungen zum ehemaligen Reichs- und Königskloster Lorsch
}

\section{Christian Sapin}

\section{OpenEdition}

\section{Journals}

Édition électronique

URL : http://journals.openedition.org/ifha/811

DOI : 10.4000/ifha.811

ISSN : 2198-8943

\section{Éditeur}

IFRA - Institut franco-allemand (sciences historiques et sociales)

Référence électronique

Christian Sapin, «ERICSSON, Ingolf, SANKE, Markus, Aktuelle Forschungen zum ehemaligen Reichs- und Königskloster Lorsch », Revue de l'IFHA [En ligne], Date de recension, mis en ligne le 01 janvier 2005, consulté le 22 septembre 2020. URL : http://journals.openedition.org/ifha/811 ; DOI : https://doi.org/ 10.4000/ifha.811

Ce document a été généré automatiquement le 22 septembre 2020.

(CIFHA 


\title{
ERICSSON, Ingolf, SANKE, Markus, Aktuelle Forschungen zum ehemaligen Reichs- und Königskloster Lorsch
}

\author{
Christian Sapin
}

La reprise des recherches sur le terrain de l'abbaye de Lorsch, ainsi que plusieurs rencontres sur place de spécialistes, ont permis une réévaluation des données et un premier regroupement des analyses de plusieurs auteurs débouchant sur un ouvrage, désormais indispensable pour approfondir la connaissance de ce grand site. On peut se réjouir que plusieurs universitaires de Bamberg aient pris à coeur un tel projet. Il s'agit aussi d'un projet de recherche et d'un chantier-école où sont gérées aussi bien la documentation ancienne que de nouvelles vérifications sur le terrain. Entre 1998 et 2002, quatre rencontres ont déjà été l'occasion de faire le point et sont ici rapportées. À partir des sources, H. SCHEFFERS rappelle quelques problématiques soulevées à propos notamment du fameux cloître et de l'interprétation de la Chronique sous l'abbé Richbod (r. 784-804). Les sources évoquent claustrum, dormitorium, les autres dispositions claustrales étant plus tardives. La question des sources sur les bâtiments claustraux de Lorsch et d'autres sites emblématiques est reprise, développée et mise en perspective dans le même volume par H. R. SENNHAUSER (" Nachrichten zum Baubetrieb süddeutscher und nordschweizerischer Klöster im frühen und hohen Mittelalter ») ; les comparaisons avec Saint-Gall, notamment à propos de l'utilisation du bois et autres matériaux, ou encore de l'atrium, éclairent les recherches sur Lorsch. D'autres aspects de l'église (chœur, tombe sainte ou autel) sont également relatés avant une réflexion globale par Th. LUDWIG sur sa démarche pour la " reconstitution » du monastère à côté d'autres grands sites carolingiens comme Steinbach étudié par l'auteur. Celui-ci a livré des maquettes de Lorsch et de Seligenstadt (1996) où s'imposent les parallèles, ce qui était loin d'être le cas dans les dessins en perspectives des auteurs anciens pour les mêmes constructions.

L'essentiel de l'ouvrage, à la suite de ces trente pages d'ouverture (et avant plusieurs annexes importantes de H.R. Sennhauser déjà cité, de S. SCHOLZ sur les inscriptions et graffiti, de M. JANDEJSEK à propos d'un sondage sur un secteur funéraire, et une 
contribution de A. HUBEL sur Regensburg et Lorsch à propos de la Torhalle), est constitué par une description détaillée des campagnes de 1998 et 1999 : description des couches, dessins des maçonneries nouvellement fouillées ou relevés, numérotation des us, diagramme, mobilier retrouvé. On signalera en particulier les fragments en opus sectile provenant peut-être du sol de la première église (fin VIIIe s.), terres cuites ornées, enduits peints, éléments de parure, outils... dont les datations s'étalent sur la longue durée du site. On retiendra l'importante contribution de J. MULLER qui pour les bâtiments au sud de l'église (Südosttor) a repris la documentation des travaux de 1934-37 et qui, grâce aux récentes campagnes et aux sources textuelles, propose plusieurs niveaux d'interprétation sur la fonction domestique du bâtiment avec des comparaisons pour les latrines. Au final, en dépit de l'effet juxtaposé, l'ensemble de l'ouvrage offre de riches contributions à différents niveaux de lecture où l'historien, l'historien de l'art et l'archéologue trouveront de quoi renouveler en de nombreux points leur vision d'un des grands sites carolingiens.

Christian SAPIN (Centre National de la Recherche Scientifique) 